\title{
Jonathon A. Nye: Radiologic physics taught through cases
}

\author{
Thieme, New York Stuttgart Delhi Rio de Janeiro, 2020, 158 p., format $25.5 \times 17.5 \times 1 \mathrm{~cm}, 231$ \\ illustrations, ISBN 978-1-62623-967-8
}

\section{Bruno Grignon ${ }^{1}$}

Received: 15 September 2020 / Accepted: 17 September 2020 / Published online: 25 September 2020

(c) Springer-Verlag France SAS, part of Springer Nature 2020

Physics is not only a key component of the American Board of Radiology core and certifying examinations, but also an essential tool for understanding and practicing radiology.

This book aims at revisiting essential physics concepts by means of diagnostic radiology scenarios commonly encountered during everyday practice, to quickly convey essential information.

It is divided into seven technology-specific chapters, subsequently devoted to fluoroscopy, mammography, computed tomography, magnetic resonance imaging, nuclear medicine, ultrasound imaging, and image processing.

Each chapter is organized in the same way, encompassing ten topics. For each of them, a case-based presentation, preceded by a concise general introduction, provides a brief explanation of physical factors underlying the image's creation and displayed contrast. It is followed by review questions, with correct answers at the end of the book, as well as end-of-chapters references.

Along with the handbook format, this work includes complimentary access to a digital copy on https://medone.thiem e.com.

The author is Jonathon A. Nye, Associate Professor, Department of Radiology and Imaging Sciences, Emory
University School of Medicine, Atlanta, Georgia. A panel of 11 American contributors have collaborated in writing this book.

The book offers a vivid and attractive presentation. Concise, easy to use, and clearly organized, it encompasses the main challenging physics concepts for daily practice in medical imaging.

As a result, chiefly devoted to residents prepping for the radiology core examination review, it may also be a useful and practical tool for early-career radiologists, as well as seasoned physicians.

Author contribution BG: manuscript writing and editing.

\section{Compliance with ethical standards}

Conflict of interest The author declares he has no conflict of interest.

Publisher's Note Springer Nature remains neutral with regard to jurisdictional claims in published maps and institutional affiliations.
Bruno Grignon

b.grignon@chu-nancy.fr

1 Universite de Lorraine, Nancy, France 